\title{
Estimation of Tropical Cyclone Intensity in the North Atlantic and Northeastern Pacific Basins Using TRMM Satellite Passive Microwave Observations
}

\author{
HAIYAN JIANG \\ Department of Earth and Environment, Florida International University, Miami, Florida \\ Cheng TAO \\ Department of Earth and Environment, Florida International University, Miami, Florida, and Lawrence Livermore \\ National Laboratory, Livermore, California \\ YONGXIAN PEI \\ Department of Earth and Environment, Florida International University, Miami, Florida
}

(Manuscript received 8 April 2018, in final form 2 November 2018)

\begin{abstract}
A statistical passive microwave intensity estimation (PMW-IE) algorithm for estimating the intensity of tropical cyclones (TCs) in the North Atlantic and northeastern and central Pacific basins is developed and tested. The algorithm is derived from Tropical Rainfall Measuring Mission (TRMM) Microwave Imager (TMI) 85-GHz brightness temperatures and near-surface rain-rate retrievals to provide objective estimates of current maximum sustained surface winds (Vmax) and 6-h future Vmax of TCs. The full record of TRMM data (1998-2013) including 2326 TMI overpasses of 503 TCs is separated into dependent samples (1998-2010) for model development and independent samples (2011-13) for model verification. The best track intensities are used as dependent variables in a stepwise multiple-regression approach. Separately for each basin, three regression models are derived using selected 1) $85-\mathrm{GHz}$-only variables, 2) rain-rate-only variables, and 3) combined $85-\mathrm{GHz}$ and rain variables. The algorithms are evaluated using independent samples and those with contemporaneous aircraft-reconnaissance measurements. Rain-only and combined models perform better than the 85-GHz-only model. Lower errors are found for estimating the 6-h future Vmax than estimating the current Vmax using all three models. This suggests that it is optimal to use passive-microwave-retrieved rain variables observed a few hours earlier to estimate TC intensity. The MAE (RMSE) of 6-h future Vmax is $9(12) \mathrm{kt}\left(1 \mathrm{kt} \approx 0.51 \mathrm{~m} \mathrm{~s}^{-1}\right)$ when testing the combined models with ATL and EPA independent samples. Aircraft-reconnaissance-based independent samples yields a MAE of $9.6 \mathrm{kt}$ and RMSE of $12.6 \mathrm{kt}$ for estimating 6-h future Vmax.
\end{abstract}

\section{Introduction}

Wind damages caused by tropical cyclones (TCs) are closely related to their size, wind structure, and maximum sustained wind speed intensity. To make accurate TC intensity forecasts, the first step is to accurately estimate the current intensity of TCs. It remains a great challenge to develop and improve objective techniques to estimate a TC's intensity. Since it was developed over three decades ago, the satellite-based Dvorak technique (DT) has been an important operational tool to estimate TC intensity (Dvorak 1972, 1984; Velden et al. 1998).

Corresponding author: Dr. Haiyan Jiang, haiyan.jiang@fiu.edu
This technique was based on an algorithm applied to both geostationary visible and infrared (IR) satellite images. The original algorithm is subjective and dependent on interpretations of TC attributes by different analysts, and therefore can result in different intensity estimates of the same storm. The automatic version of the algorithm - the objective Dvorak technique (ODT) developed by Velden et al. (1998) — can overcome the subjective problem, but is not applicable to tropical depressions or weak tropical storms. As presented in Olander and Velden (2007), the advanced Dvorak technique (ADT) is the most recent version of ODT. It provided many improvements and advancements over the ODT and can make intensity estimates for all TCs 
including weak storms. The latest upgrades and enhancements of ADT were presented in Olander and Velden (2018).

Other approaches using IR satellite imagery to automatically estimate TC intensity have emerged. A multivariate regression algorithm introduced by Kossin et al. (2007) was for historical TC intensity reanalysis using best track intensity within $3 \mathrm{~h}$ of aircraft-reconnaissance data. The deviation angle variance (DAV) technique was originally developed by Piñeros et al. (2008, 2011). It calculates the gradient of the IR brightness temperature field to correlate with TC intensity. A modified version of DAV was presented in Ritchie et al. $(2012,2014)$ for TCs in the North Atlantic and North Pacific Ocean basins, respectively. A "feature analogs in satellite imagery (FASI)" technique was introduced by Fetanat et al. (2013), which was developed from historical hurricane IR satellite data using a $k$-nearest-neighbor algorithm. The technique was trained and validated using aircraftreconnaissance-based best track data. More recently, Pradhan et al. (2018) presented a convolutional neural network (CNN)-based TC intensity estimation technique from IR satellite imagery. It was tested using an aircraftreconnaissance-based best track dataset as well. Unlike the subjective DT and objective ADT, all of the abovementioned IR satellite-based algorithms were reported in development stage and were not implemented for realtime usage.

The maximum wind of hurricanes usually occurs within the eyewall region. The visible and IR images only show the cloud-top structure of a TC and cannot measure the detailed structure at lower levels, especially in the eyewall (Kidder and Vonder Haar 1995). The advantage of passive microwave channels is that they allow penetration into precipitating clouds, which is a very favorable feature especially when a central dense overcast exists in visible and IR images. Satellite passive microwave sounders such as the Advanced Microwave Sounding Unit (AMSU) can measure the warm-core anomaly, which has been used to estimate TC intensities (Kidder et al. 2000). There are two AMSU-based TC intensity estimation algorithms available in real time or near-real time. Both of them use a multilinear regression approach. The University of Wisconsin-Madison Cooperative Institute for Meteorological Satellite Studies (CIMSS) AMSU-based algorithm was first documented in Brueske and Velden (2003), and updated in later and recent conference presentations (Herndon and Velden 2006; Herndon et al. 2018). The Colorado State University Cooperative Institute for Research in the Atmosphere (CIRA) AMSUbased algorithm was first documented in Demuth et al. (2004, 2006), and updated in a recent conference presentation (Chirokova et al. 2018). The recent updates of both CIMSS and CIRA AMSU-based algorithms included data input from other sounders, such as the sounding channels of Special Sensor Microwave Imager/ Sounder (SSMIS), Advanced Technology Microwave Sounder (ATMS), and the future Time-Resolved Observation of Precipitation structure and storm intensity with a Constellation of Smallsats (TROPICS). Realtime implement efforts are reported by CIMSS and CIRA for the AMSU-based algorithms in conference presentations (Herndon and Velden 2006; Herndon et al. 2018; Chirokova et al. 2018), but no refereed documents are available at the time of this writing.

Passive microwave imagers measure upwelling radiances at frequencies near $6,10,19,22,37$, and 85-91 GHz. Radiances at these channels are influenced strongly by emission from liquid water drops and/or water vapor, and/or by the scattering of radiation by ice particles. These characteristics make the microwave sensors well suited to the estimation of rain. With or without formally retrieving rain rates, these channels are useful for assessing the distribution of rain in a TC. Observations in these channels are suggestive of the upward motion and latent heating that are critical for driving a TC's circulation. Therefore, these channels offer unique perspectives to estimating TC intensities.

Previous studies have demonstrated that the storm intensity is very well correlated with variables associated with $85-\mathrm{GHz}$ brightness temperatures and rain rates in the inner core. The $85-\mathrm{GHz}$ microwave channel is sensitive to ice particles in precipitation systems. These precipitationsized particles scatter the upwelling radiation and reduce the brightness temperature. Therefore, a low $85-\mathrm{GHz}$ brightness temperature can therefore imply increased precipitation rate and convective intensity. Glass and Felde (1992) examined the relationship between the $85-\mathrm{GHz}$ brightness temperature and TC intensity. They found that the percentage of pixels having brightness temperatures below $220-230 \mathrm{~K}$ is highly correlated with TC intensity. Rao and MacArthur (1994) found that the microwave-derived rainfall rates in the inner-core region were highly correlated with 24-h future typhoon intensity (correlation coefficient $=0.68$ ). Similar results were found by Rodgers et al. (1994) using the western North Atlantic TCs. Cecil and Zipser (1999) examined various ice-scattering signature parameters from the $85-\mathrm{GHz}$ observations. They found high correlations $(0.5-$ 0.8 ) between the mean $85-\mathrm{GHz}$ polarization-corrected brightness temperature (PCT; Spencer et al. 1989) in the inner core and the current and 24-h future TC intensity.

These previous studies have provided the proof of concept of using microwave brightness temperatures and retrieved rain rates to estimate TC intensity. Bankert and Tag (2002) made a step forward by developing an 
TABLE 1. Spatial resolution at 85-91 GHz, other frequencies, and operating years of satellite passive microwave radiometers mentioned in section $2 \mathrm{a}$.

\begin{tabular}{lcccc}
\hline \hline \multicolumn{1}{c}{ Sensor } & Frequency $(\mathrm{GHz})$ & Spatial resolution $\left(\mathrm{km}^{2}\right)$ & Other frequencies $(\mathrm{GHz})$ & Years \\
\hline SSM/I (F15) & 85.5 & $15 \times 13$ & $19,22,37$ & $1987-$ present \\
SSMIS (F16, 17, 18, 19) & 91 & $14 \times 13$ & $19,22,36.5,50,60,183$ & $2003-$ present \\
AMSR-E & 89 & $6 \times 4$ & $6,10,18,23,36.5$ & $2002-11$ \\
AMSR2 & 89 & $5 \times 3$ & $6,10,18,23,36.5$ & $2012-$ present \\
TMI & 85.5 & $7 \times 5$ (before boost), & $10,19,22,37$ & $1997-2014$ \\
GMI & 89 & $8 \times 6$ (after boost) & $10,18,23,36.5,165,183$ & $2014-$ present \\
\hline
\end{tabular}

automatic TC intensity estimation technique using both the 85-GHz and derived rain-rate imagery. The technique was based on feature selection using a $k$-nearest-neighbor algorithm. It was updated in a recent conference presentation (Bankert and Cossuth 2016) by adding 37-GHz features as input. The detailed error statistics of all abovementioned IR-, AMSU-, and SSM/I-based algorithms from peer-reviewed sources will be summarized in section 5 (Table 9).

All of these passive-microwave-imager-based studies used the lower-resolution SSM/I data. The coarse resolution of the SSM/I can reduce the heavy rain rates that can be observed otherwise. There are higher-resolution passive microwave imager data available from the Advanced Microwave Scanning Radiometer (AMSR, including AMSR-E, then AMSR-2), Tropical Rainfall Measuring Mission (TRMM) Microwave Imager (TMI), and the recent Global Precipitation Mission (GPM) Microwave Imager (GMI). Table 1 shows a comparison of the spatial resolutions at $85-91 \mathrm{GHz}$ of these sensors. In the current study, variables from the $85-\mathrm{GHz}$ channel and derived rain rate from the higherresolution TMI observations are used to develop a statistical technique called Passive Microwave Intensity Estimation (PMW-IE) algorithm for estimating the intensity of TCs in the North Atlantic (ATL) and northeast and central Pacific (EPA) basins, respectively. The data and methodology are described in section 2 . In section 3, the selection of independent variables and the regression analysis are discussed. Evaluations of the model performance using independent samples are discussed in section 4 , followed by a discussion of the results as compared with other TC intensity estimation algorithms in section 5. Conclusions and future work are presented in section 6 .

\section{Data and methodology}

The data used in this study include observations from TRMM. One of the main goals of the TRMM project is to monitor TCs globally (Simpson et al. 1988). The TRMM satellite was launched in November of 1997 and ended operation in 2014. This platform provides coverage of latitudes from $36^{\circ} \mathrm{S}$ to $36^{\circ} \mathrm{N}$. The TMI on TRMM is a conically scanning 9-channel microwave radiometer that provides brightness temperatures in these channels. The instrument operates at 10.65-, 19.35-, 21.3-, 37.0-, and $85.5-\mathrm{GHz}$ frequencies. To reduce the ambiguity between low brightness temperatures due to ice scattering and low brightness temperatures due to radiometrically cold sea surface, Spencer et al. (1989) derived the $85-\mathrm{GHz}$-channel PCT:

$$
\mathrm{PCT}_{85}=1.82 T_{85 \mathrm{v}}-0.82 T_{85 \mathrm{~h}},
$$

where $\mathrm{v}$ and $\mathrm{h}$ subscripts are for vertical and horizontal polarizations, respectively. The $2 \mathrm{~A} 12$ surface rainfall product uses the full spectrum of TMI frequencies to make rain estimates. The product is based on the NASA GPROF algorithm (Kummerow et al. 1996). Version 7 of the TMI $2 \mathrm{~A} 12$ product is used in this study.

In this study, a TMI dataset from the full TRMM record (1998-2013) for the ATL and EPA TCs is used. It includes all named storms with intensity ranging from tropical depression to category 1-5 hurricane stages. To select TC overpasses from TRMM observations, the TRMM Tropical Cyclone Precipitation Feature (TCPF) database (http://tcpf.fiu.edu; Jiang et al. 2011) is used. This database currently includes global TCs that were observed by the TRMM satellite during 1998-2013. In the database, the TC positions and maximum sustained wind (Vmax) intensity on the satellite overpass time were linearly interpolated from the best track data. The best track data for the ATL and EPA basins are from HURDAT2 (Landsea and Franklin 2013).

The TMI's swath width is $878 \mathrm{~km}(760 \mathrm{~km}$ before the TRMM orbital boost in August 2001). Because of the limitation of the swath width, not all TCs were well observed by the TMI. To be included in the dataset of this study, an overpass must capture a $250-\mathrm{km}$ radius from the TC center. At the TMI observation time, the storm must be over water, and will be over water in the following $6 \mathrm{~h}$. The algorithm is developed for ATL and EPA samples separately. The final dataset includes 1219 
TABLE 2. Numbers of TMI samples and numbers of TCs (in parentheses) for both the dependent (1998-2010) and independent (2011-13) datasets in different TC intensity categories according to Saffir-Simpson category for the ATL and EPA basins.

\begin{tabular}{|c|c|c|c|c|}
\hline & \multicolumn{2}{|c|}{ ATL } & \multicolumn{2}{|c|}{ EPA } \\
\hline & $\begin{array}{l}\text { Dependent } \\
(1998-2010)\end{array}$ & $\begin{array}{l}\text { Independent } \\
(2011-13)\end{array}$ & $\begin{array}{l}\text { Dependent } \\
(1998-2010)\end{array}$ & $\begin{array}{l}\text { Independent } \\
(2011-13)\end{array}$ \\
\hline Tropical depression (TD; <34 kt) & $254(118)$ & $48(25)$ & $398(159)$ & $110(42)$ \\
\hline Tropical storm (TS; 34-63 kt) & $398(144)$ & $157(39)$ & $299(152)$ & $85(43)$ \\
\hline Category 1-2 hurricanes (64-95 kt) & $201(67)$ & $45(16)$ & $98(54)$ & $27(18)$ \\
\hline Category 3-5 hurricanes ( $>96 \mathrm{kt}$ ) & $93(33)$ & $4(2)$ & $63(31)$ & $12(7)$ \\
\hline All TCs & $962(191)$ & $257(48)$ & $870(213)$ & $237(51)$ \\
\hline
\end{tabular}

TMI overpasses of 239 TCs in ATL and 1107 overpasses of 264 TCs in EPA. It is further separated into dependent and independent samples as shown in Table 2. The dependent sample will be used for model development, while the independent sample will be for verification. As seen in Table 2, the dependent sample of ATL (EPA) includes 962 (870) overpasses of 191 (213) TCs during 1998-2010, while independent sample of ATL (EPA) includes 257 (237) overpasses of 48 (51) TCs during 2011-13. Table 2 also presents the distribution of samples for different TC intensity categories.

To develop the model, first, the dependent samples are used to calculate the correlation coefficients between TMI-derived variables and best track current and 6-h future intensities and the correlation coefficient matrix among TMI-derived variables. A group of variables are selected based on the correlation coefficients and significance test results. Stepwise multiple linear regressions are then performed using variables derived from the dependent sample to generate a method for estimating the current TC intensity and 6-h future TC intensity. Last, the independent sample is used to evaluate the performance of the newly developed method. The error statistics of the model is generated by comparing the best track current and 6-h future intensities with the estimated values.

\section{Selection of variables and regression analysis}

\section{a. Selection of variables}

To develop the TC intensity estimation model, our first step is to select passive microwave variables that are well correlated with TC intensity Vmax. According to Cecil and Zipser (1999) and other previous studies mentioned in the introduction section, both $85-\mathrm{GHz}$ PCT and rain-rate-related parameters in the inner core are considered. We have tested a large number of variables including the mean, median, standard deviation, and maximum/minimum of $85-\mathrm{GHz}$ PCT and rain rate in the inner core and the fractional inner-core area covered by $85-\mathrm{GHz}$ PCT less than a certain value or rain rate greater than a certain value. Although the storm inner-core size is generally defined as within $\sim 100 \mathrm{~km}$ from the TC center (Rodgers and Pierce 1995; Cecil and Zipser 1999), it actually varies from storm to storm (Jiang et al. 2013). We have tested eight choices of the inner-core radius including 75, 100, 125, 150, 175, 200, 225 , and $250 \mathrm{~km}$ to calculate above $85-\mathrm{GHz} \mathrm{PCT}$ and rain-rate-related variables. The linear correlation coefficients between these variables and Vmax and the corresponding $\mathrm{p}$ values from Student's $t$ tests are calculated. Table 3 lists the variables with correlation coefficients significant at the $99.99 \%$ level for all eight different radii of inner core. Only these variables will be used as candidate estimators of TC intensity.

However, it is necessary to choose an optimal radius of the inner core for calculating these variables. Figure 1 plots the correlation coefficients between the 12 variables and Vmax and 6-h future Vmax as a function of inner-core radius choices for ATL and EPA samples, respectively. The correlation coefficients are not very sensitive to the inner-core radius choices. But we found that when using $100(75) \mathrm{km}$ as the inner-core radius for ATL (EPA) samples, the highest multiple linear correlation coefficients are achieved. Among all the variables, the inner-core fractional area covered by heavy rain (H_RA) and unconditional mean rain rate in the inner (U_RR) have the highest correlation coefficients with Vmax and 6-h future Vmax. In this study, unconditional mean rain rate is defined as the average of all rain-rate values including zero within the inner-core region, whereas the conditional mean rain rate is defined as the average of all nonzero rain-rate values within the inner core. Correlation coefficients of these two variables with Vmax and 6-h future Vmax are the highest at 100-km inner-core radius for ATL samples and at $75-\mathrm{km}$ radius for EPA samples. Therefore, we will use $100 \mathrm{~km}(75 \mathrm{~km})$ as the inner-core radius for ATL (EPA) samples for calculating the variables listed in Table 2 for the model development verification in the following sections.

Although this study is mainly for algorithm development and testing using a homogeneous historical dataset and not for real-time usage yet, we should always keep 
TABLE 3. List of 85-GHz and rain variables in the inner core derived from passive microwave observations.

\begin{tabular}{|c|c|c|}
\hline Variables & Description & Unit \\
\hline \multicolumn{3}{|l|}{$85 \mathrm{GHz}$} \\
\hline MEANPCT & Mean $85-\mathrm{GHz}$ PCT & $\mathrm{K}$ \\
\hline FRAC275 & $\begin{array}{c}\text { Fractional area covered by } \\
85-\mathrm{GHz} \mathrm{PCT} \leq 275 \mathrm{~K}\end{array}$ & $\%$ \\
\hline FRAC250 & $\begin{array}{c}\text { Fractional area covered by } \\
85-\mathrm{GHz} \mathrm{PCT} \leq 250 \mathrm{~K}\end{array}$ & $\%$ \\
\hline FRAC225 & $\begin{array}{c}\text { Fractional area covered by } \\
85-\mathrm{GHz} \text { PCT } \leq 225 \mathrm{~K}\end{array}$ & $\%$ \\
\hline FRAC200 & $\begin{array}{l}\text { Fractional area covered by } \\
85-\mathrm{GHz} \text { PCT } \leq 200 \mathrm{~K}\end{array}$ & $\%$ \\
\hline \multicolumn{3}{|l|}{ Rain } \\
\hline U_RR & Unconditional mean rain rate & $\mathrm{mm} \mathrm{h}^{-1}$ \\
\hline C_RR & Conditional mean rain rate & $\mathrm{mm} \mathrm{h}^{-1}$ \\
\hline L_RR & $\begin{array}{l}\text { Mean light rain (rain rate } \\
\text { between } 0 \text { and } 5 \mathrm{~mm} \mathrm{~h}^{-1} \text { ) rate }\end{array}$ & $\mathrm{mm} \mathrm{h}^{-1}$ \\
\hline H_RR & $\begin{array}{l}\text { Mean heavy rain (rain rate } \\
\quad \geq 5 \mathrm{~mm} \mathrm{~h}^{-1} \text { ) rate }\end{array}$ & $\mathrm{mm} \mathrm{h}^{-1}$ \\
\hline RA & Fractional area covered by rain & $\%$ \\
\hline L_RA & Fractional area covered by light rain & $\%$ \\
\hline H_RA & Fractional area covered by heavy rain & $\%$ \\
\hline
\end{tabular}

real-time application in mind. In real time, a satellite data latency of $2-4 \mathrm{~h}$ is always possible and a real concern. Our approach is to evaluate the correlations of the TMI-derived variables with the 6-h future Vmax as well. If high correlations also exist as we expected, we could still use the late information to estimate the current intensity (at $\sim 6$-h future synoptic time relative to the satellite observation time).

Table 4 provides the linear correlation coefficients between the 12 variables listed in Table 2 calculated at the optimal inner-core radius and TC current $(t=0 \mathrm{~h})$ and 6-h future $(t=6 \mathrm{~h})$ Vmax for ATL and EPA dependent samples. Since the $85-\mathrm{GHz}$ brightness temperatures and rain retrievals are from different products, we treat $85-\mathrm{GHz}$ and rain variables separately in order to isolate their individual contributions to TC intensity estimates. In Table 4, the multiple linear correlation coefficients for the five $85-\mathrm{GHz}$ variables, seven rain variables, and twelve combined $85-\mathrm{GHz}$ and rain variables are also provided, respectively. It is seen from Table 4 that rain variables are better correlated with Vmax and 6-h future Vmax than $85-\mathrm{GHz}$ variables. The multiple linear correlation coefficients with Vmax are $0.74(0.69)$ for $85-\mathrm{GHz}$ variables and $0.86(0.80)$ for rain variables for ATL (EPA) samples. After combining all 12 rain and $85-\mathrm{GHz}$ variables, the coefficients with Vmax are the same as the rain variables. These correlations coefficients are higher than those found in Cecil and Zipser (1999) using 85-GHz-only parameters. Slightly better correlations are seen between these satellite-derived variables and 6-h future Vmax. This justifies the usefulness of microwave data even with 2-4-h latency in real time.

\section{b. Regression model}

Based on the results above, the PMW-IE model is developed to provide TC intensity estimation. The approach is similar to the Statistical Hurricane Intensity Prediction Scheme (SHIPS; DeMaria and Kaplan 1994), in which a multiple linear regression method was used to predict TC future intensity change from a set of climatology and persistence, and environmental parameters. A similar approach was also used in the CIRA AMSUbased intensity estimates (Demuth et al. 2004, 2006). In this study, three regression models will be made for each basin using 85-GHz-only, rain-only, and combined 85-GHz and rain variables. As stated in Franke (2010), multicollinearity is a problem and should be avoided for multilinear regressions. Predictor variables that are highly correlated could cause overfitting problems. Therefore, for each regression model, a correlation coefficient matrix among all the candidate variables is calculated and reviewed to eliminate variables that are highly correlated with each other (correlation coefficient above 0.8). For the remaining variables, stepwise regressions using the International Mathematics and Statistics Library (IMSL) software are performed to further filter out variables with little contributions to the model. Table 5 shows the final regression variables used in each model and their corresponding normalized coefficients. A "_-" symbol without a number value means that this variable is not used in the corresponding model. For example, only the inner-core fractional area covered by $85-\mathrm{GHz}$ PCT $\leq 275 \mathrm{~K}$ (FRAC275), $85-\mathrm{GHz}$ PCT $\leq$ $225 \mathrm{~K}$ (FRAC225), and 85-GHz PCT $\leq 200 \mathrm{~K}$ (FRAC200) are used in $85-\mathrm{GHz}$-only regression models in both basins. But note that their regression coefficients are different for ATL versus EPA and for estimating Vmax versus 6-h future Vmax.

Table 5 shows that FRAC275 is the most influential parameter when using $85-\mathrm{GHz}$-only regression equations in estimating both Vmax and 6-h future Vmax in the ATL basin. But for the EPA basin, FRAC225 is more influential than FRAC275 for estimating Vmax. For rain-only and combined $85-\mathrm{GHz}$ and rain regression models, the single most influential parameter is H_RA, whose normalized coefficients are much higher than those of other variables remained in the models. In the regressions using combined $85-\mathrm{GHz}$ and rain estimators, the rain estimators influence much more than the 85-GHz estimators. This is expected because the inner-core rain is better correlated with TC intensity. The $85-\mathrm{GHz}$ estimators explain 53\% (47\%) of the variance in $V \max$ 
(a) ATL Vmax

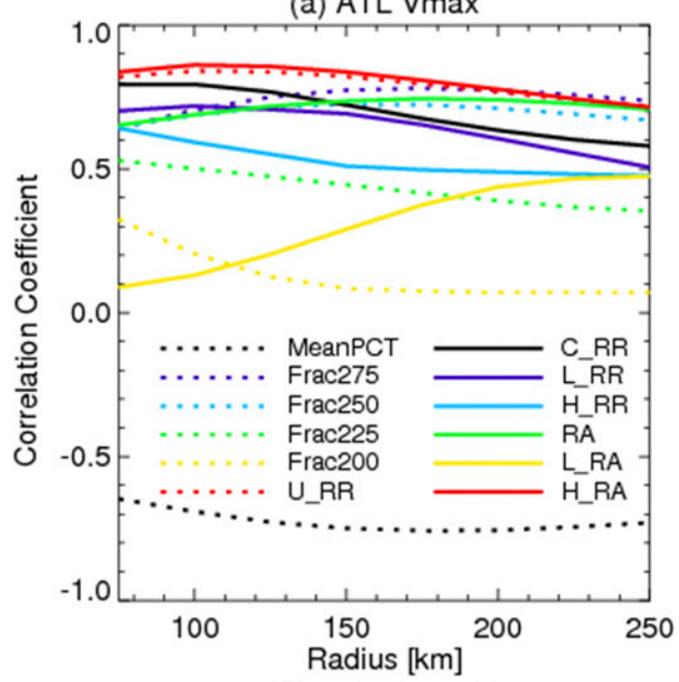

(c) ATL 6-h Future Vmax

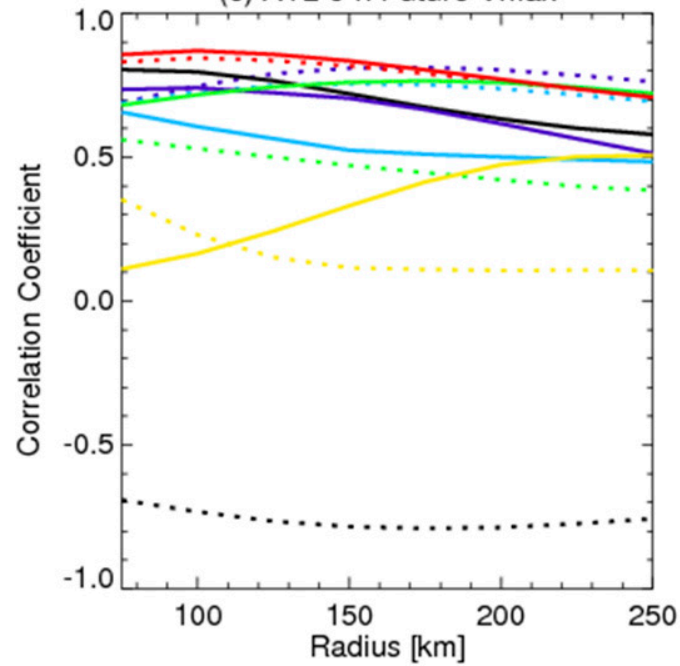

(b) EPA Vmax

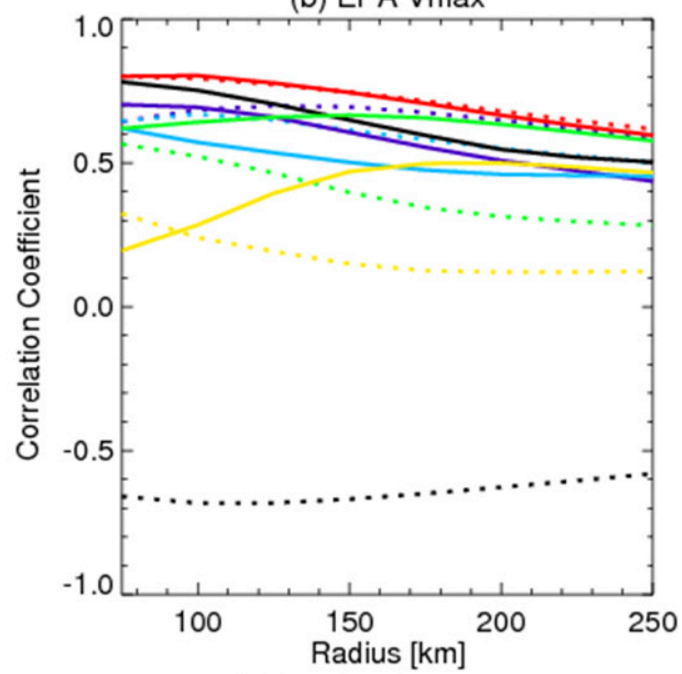

(d) EPA 6-h Future Vmax

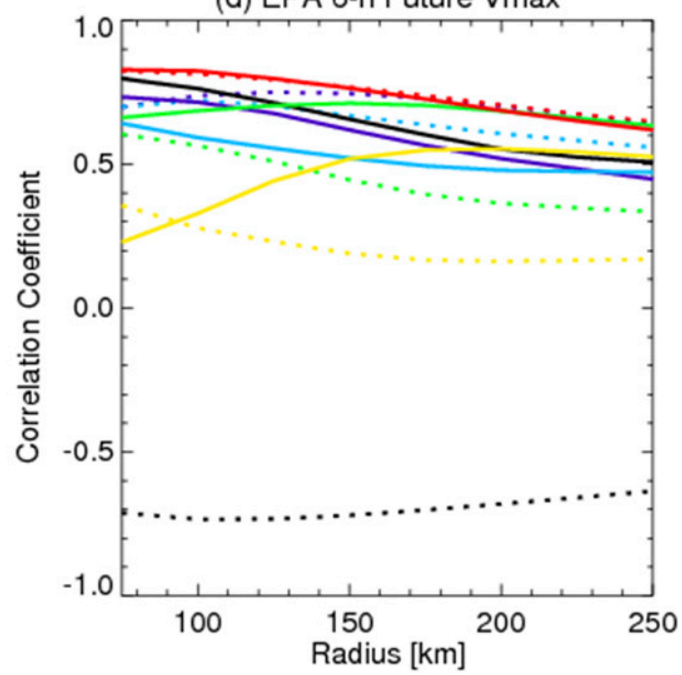

FIG. 1. Correlation coefficients between the 12 variables listed in Table 2 and the best track Vmax as a function of inner-core radius for (a) ATL and (b) EPA dependent samples. (c), (d) As in (a) and (b), respectively, but for correlation coefficients between the 12 variables listed in Table 2 and the best track 6-h future Vmax.

and $59 \%(54 \%)$ in 6-h future Vmax for ATL (EPA) samples. The rain estimators explain a higher percentage of the variance in Vmax and 6-h future Vmax (between $75 \%$ and $77 \%$ for ATL and between $65 \%$ and $69 \%$ for EPA) than the $85-\mathrm{GHz}$ estimators. After combining $85-\mathrm{GHz}$ and rain estimators, a similar or slightly higher percentage is achieved. Regression models for ATL explain higher percentages of the variance than their corresponding models for EPA. This suggests that it is beneficial to separate different basins when developing the algorithm. Regression models for estimating 6-h future Vmax explain higher percentages of the variance than their corresponding models for estimating Vmax. This not only suggests that the satellite data latency can be resolved this way, but it also indicates that a higher accuracy might be achieved by using the 6-h future Vmax estimation models.

\section{Independent verification}

To evaluate the PMW-IE algorithm developed above, independent datasets for ATL and EPA basins are applied to each regression model accordingly. The results are compared with the best track. As shown in Table 6, for the 257 ATL independent samples, the 85-GHz-only model explains $37 \%$ of the Vmax variance and $44 \%$ of the 6-h future Vmax variance. The rain-only model explains $54 \%$ of the Vmax variance and $58 \%$ of the $6-\mathrm{h}$ future Vmax variance. The combined algorithm explains very similar percentages of Vmax and 6-h future 
TABLE 4. Linear correlation coefficients $R$ between satellite-derived variables and TC current $(t=0 \mathrm{~h})$ and 6 -h future $(t=6 \mathrm{~h}) \mathrm{Vmax}$. Multiple linear correlation coefficients using five $85-\mathrm{GHz}$ variables, seven rain variables, and combined $85-\mathrm{GHz}$ and rain variables are also presented. All the coefficients are significant at the $99.99 \%$ level based on Student's $t$ tests.

\begin{tabular}{|c|c|c|c|c|}
\hline \multirow[b]{2}{*}{ Variables } & \multicolumn{2}{|c|}{ ATL cases $(n=962)$} & \multicolumn{2}{|c|}{ EPA cases $(n=870)$} \\
\hline & $t=0 \mathrm{~h}$ & $t=6 \mathrm{~h}$ & $t=0 \mathrm{~h}$ & $t=6 \mathrm{~h}$ \\
\hline MeanPCT & -0.69 & -0.73 & -0.66 & -0.71 \\
\hline Frac275 & 0.70 & 0.75 & 0.64 & 0.70 \\
\hline FRAC250 & 0.69 & 0.73 & 0.65 & 0.70 \\
\hline FRAC225 & 0.50 & 0.53 & 0.57 & 0.60 \\
\hline FRAC200 & 0.21 & 0.23 & 0.32 & 0.36 \\
\hline All $85-\mathrm{GHz}$ variables & 0.74 & 0.78 & 0.69 & 0.74 \\
\hline U_RR & 0.84 & 0.84 & 0.80 & 0.82 \\
\hline C_RR & 0.79 & 0.80 & 0.78 & 0.80 \\
\hline L_RR & 0.72 & 0.74 & 0.70 & 0.73 \\
\hline H_RR & 0.59 & 0.61 & 0.62 & 0.64 \\
\hline $\mathrm{RA}$ & 0.69 & 0.72 & 0.62 & 0.66 \\
\hline L_RA & 0.13 & 0.16 & 0.20 & 0.23 \\
\hline H_RA & 0.86 & 0.87 & 0.80 & 0.83 \\
\hline All rain variables & 0.86 & 0.87 & 0.80 & 0.83 \\
\hline Combined $85-\mathrm{GHz}$ and rain variables & 0.86 & 0.87 & 0.80 & 0.83 \\
\hline
\end{tabular}

Vmax variances to the rain-only model. The mean absolute error $(\mathrm{MAE})$ of $V \max$ is $11.47 \mathrm{kt}\left(1 \mathrm{kt} \approx 0.51 \mathrm{~m} \mathrm{~s}^{-1}\right)$ using the 85-GHz-only algorithm and decreases to 9.77 and $9.74 \mathrm{kt}$ when using rain-only and combined algorithms, respectively. The root-mean-square error (RMSE) of Vmax is $15.31 \mathrm{kt}$ using the 85-GHz-only algorithm. Using the rain estimators substantially reduce the RMSE of Vmax to 12.83 (12.84) kt by the rain-only (combined) algorithm. The standard deviation of residuals (STD) of Vmax is $15.24 \mathrm{kt}$ for the $85-\mathrm{GHz}$-only algorithm, and decreases to 12.81 (12.83) kt for the rain-only (combined) algorithm. MAEs, RMSEs, and STDs of 6-h future Vmax are all smaller than their corresponding values of Vmax for all three regression models.
For the 237 EPA independent samples, all three models explain higher percentages of variance of Vmax and 6-h future Vmax than their corresponding values for the ATL samples, ranging from $41 \%$ to $71 \%$. Similar improvements as for ATL samples are seen for the rainonly or combined model versus the 85-GHz-only model. MAE, RMSE and STD of Vmax and 6-h future Vmax using the 85-GHz-only model are higher for EPA samples than those for ATL samples. When using rain-only and combined models, MAEs, RMSEs, and STDs of Vmax are higher for EPA samples, but those of 6-h future Vmax are lower than those for ATL samples.

The best track intensity estimates are most accurate when there were contemporaneous aircraft reconnaissance

TABLE 5. Regression variables and their corresponding normalized coefficients to estimate best track Vmax and 6-h future Vmax for the 85-GHz-only, rain-only, and combined 85-GHz and rain models in ATL and EPA, respectively. In the bottom row $R^{2}$ is the portion of total variance explained by each regression.

\begin{tabular}{|c|c|c|c|c|c|c|c|c|c|c|c|c|}
\hline & \multicolumn{6}{|c|}{ ATL } & \multicolumn{6}{|c|}{ EPA } \\
\hline & \multicolumn{2}{|c|}{$85-\mathrm{GHz}$ only } & \multicolumn{2}{|c|}{ Rain only } & \multicolumn{2}{|c|}{ Combined } & \multicolumn{2}{|c|}{ 85-GHz only } & \multicolumn{2}{|c|}{ Rain only } & \multicolumn{2}{|c|}{ Combined } \\
\hline & $t=0 \mathrm{~h}$ & $t=6 \mathrm{~h}$ & $t=0 \mathrm{~h}$ & $t=6 \mathrm{~h}$ & $t=0 \mathrm{~h}$ & $t=6 \mathrm{~h}$ & $t=0 \mathrm{~h}$ & $t=6 \mathrm{~h}$ & $t=0 \mathrm{~h}$ & $t=6 \mathrm{~h}$ & $t=0 \mathrm{~h}$ & $t=6 \mathrm{~h}$ \\
\hline MEANPCT & - & - & - & - & - & - & - & - & - & - & - & - \\
\hline FRAC275 & 16.06 & 17.38 & - & - & - & - & 11.51 & 13.24 & - & - & - & - \\
\hline FRAC250 & - & - & - & - & - & - & - & - & - & - & - & - \\
\hline FRAC225 & 10.04 & 9.56 & - & - & -3.26 & - & 12.80 & 12.40 & - & - & -1.40 & - \\
\hline FRAC200 & -8.80 & -8.26 & - & - & - & -1.81 & -7.63 & -7.22 & - & - & - & - \\
\hline U_RR & - & - & - & - & - & - & - & - & - & - & - & - \\
\hline C_RR & - & - & - & - & - & - & - & - & - & - & - & - \\
\hline L_RR & - & - & - & - & - & - & - & - & - & - & - & - \\
\hline H_RR & - & - & - & - & 1.69 & 1.48 & - & - & 2.36 & 1.79 & 2.78 & 1.79 \\
\hline $\mathrm{RA}$ & - & - & 3.36 & 4.66 & 3.04 & 4.46 & - & - & - & 1.51 & - & 1.51 \\
\hline L_RA & - & - & - & - & - & - & - & - & - & - & - & - \\
\hline H_RA & - & - & 20.98 & 20.30 & 22.20 & 20.01 & - & - & 19.23 & 19.46 & 19.93 & 19.46 \\
\hline$R^{2}$ & 0.53 & 0.59 & 0.75 & 0.77 & 0.76 & 0.77 & 0.47 & 0.54 & 0.65 & 0.69 & 0.65 & 0.69 \\
\hline
\end{tabular}


TABLE 6. Comparison of the results for independent estimations of Vmax and 6-h future Vmax using 2011-13 independent samples for $85-\mathrm{GHz}$-only, rain-only, and combined $85-\mathrm{GHz}$ and rain regression models. The $R^{2}$ value is the portion of total variance explained by each regression.

\begin{tabular}{|c|c|c|c|c|c|c|}
\hline & \multicolumn{2}{|c|}{ 85-GHz only } & \multicolumn{2}{|c|}{ Rain only } & \multicolumn{2}{|c|}{ Combined } \\
\hline & $t=0 \mathrm{~h}$ & $t=6 \mathrm{~h}$ & $=0 \mathrm{~h}$ & $t=6 \mathrm{~h}$ & $t=0 \mathrm{~h}$ & $t=t$ \\
\hline \multicolumn{7}{|l|}{$\operatorname{ATL}(n=257)$} \\
\hline$R^{2}$ & 0.37 & 0.44 & 0.54 & 0.58 & 0.55 & 0.57 \\
\hline MAE $(\mathrm{k}$ & 17 & 10 & 9.77 & 9.24 & 9.74 & 9.37 \\
\hline $\mathrm{RM}$ & 15.31 & 14.47 & 12.83 & 12.23 & 12.84 & 12.38 \\
\hline STD $(k$ & 15.24 & 14.38 & 12.81 & 12.24 & 12.83 & 12.39 \\
\hline \multicolumn{7}{|l|}{$\operatorname{EPA}(n=237)$} \\
\hline$R^{2}$ & 0 & & 0.61 & 0.71 & 0.62 & 0.71 \\
\hline MAE & 12.93 & 11.60 & 10.15 & 9.04 & 10.08 & 9.04 \\
\hline RMSE (1 & 17.49 & 15.95 & 14.05 & 12.33 & 13.97 & 12.33 \\
\hline STD (kt) & 17.43 & 15.91 & 14.07 & 12.35 & 13.99 & 12.35 \\
\hline
\end{tabular}

available. In this study, the aircraft-reconnaissance-based best track (AIRC) samples are identified if a sample was within $3 \mathrm{~h}$ of an aircraft reconnaissance. There are 38 AIRC samples out of the 257 ATL independent samples, but only five AIRC samples out of the 237 EPA independent samples. As seen in Table 7, the MAEs, RMSEs, and STDs from the ATL AIRC samples are very similar to those from all ATL independent samples in Table 6. For the EPA AIRC samples, much smaller MAEs, RMSEs, and STDs are found (around 5-7 kt, not shown). But since there are only five AIRC samples in EPA, the result might not be representative.

The scatterplots of best track Vmax and 6-h future Vmax versus the PMW-IE estimated Vmax and 6-h future Vmax for independent samples in ATL and EPA are shown in Figs. 2 and 3, respectively. The data points are generally clustered around the 1:1 line, with no significant biases found for all samples (Table 8). However, there are some outliers, especially for the $85-\mathrm{GHz}$-only model. There are less outliers for both rain-only and combined models. As seen in Table 8, all the regression models have a tendency to underestimate higher intensities and overestimate weaker intensities, but the biases are the largest for the 85-GHz-only model. Similar biases are seen between the rain-only and combined models. For example, the positive bias (overestimation) for tropical depressions in ATL decreases from $17.11 \mathrm{kt}$ of the $85-\mathrm{GHz}$-only model to 9.46 of the rain-only model and $9.17 \mathrm{kt}$ of the combined model. Much smaller biases are found for 6-h future Vmax estimations than those for Vmax for each corresponding model and basin. The largest biases are found for hurricanes in EPA, ranging between -13.59 and $-21.79 \mathrm{kt}$. All hurricanes are grouped together in Table 8's bias analysis because there are not enough samples in the major-hurricane
TABLE 7. As in Table 6, but for ATL independent AIRC samples $(n=38)$.

\begin{tabular}{lrrrrrrrrr}
\hline & \multicolumn{2}{c}{$85-\mathrm{GHz}$ only } & & \multicolumn{2}{c}{ Rain only } & & \multicolumn{2}{c}{ Combined } \\
\cline { 2 - 3 } & $t=0 \mathrm{~h}$ & $t=6 \mathrm{~h}$ & & $t=0 \mathrm{~h}$ & $t=6 \mathrm{~h}$ & & $t=0 \mathrm{~h}$ & $t=6 \mathrm{~h}$ \\
\hline$R^{2}$ & 0.32 & 0.36 & & 0.54 & 0.53 & & 0.56 & 0.54 \\
MAE (kt) & 11.38 & 10.44 & & 10.22 & 9.94 & & 9.98 & 9.62 \\
RMSE (kt) & 15.52 & 15.24 & & 13.15 & 12.88 & & 12.79 & 12.64 \\
STD (kt) & 15.64 & 15.44 & & 12.37 & 12.62 & & 12.08 & 12.46 \\
\hline
\end{tabular}

category in the independent sample (Table 2) to warrant a separate error analysis.

\section{Comparison with other TC intensity estimation techniques}

This section provides a general comparison of error statistics with other existing algorithms estimating TC intensity. Ideally, a homogeneous comparison using a homogeneous dataset is preferred. However, that will cause too much effort and is beyond the scope of this study. Here only a general comparison is provided in Table 9 to show MAEs and/or RMSEs of other techniques as published in refereed publications. Note that updates on the performance of some algorithms presented in nonrefereed sources are not included in Table 9. Since each technique is developed using very different training and validation datasets, one can only draw broad conclusions on whether the PMW-IE algorithm can make new contributions to the existing analysis of TC intensity. Based on results in section 4 , both of the rain-only model and the combined model performed much better than the 85-GHz-only model. They also performed better for estimating 6-h future Vmax than current Vmax. Therefore, the MAE and RMSE of the combined model for estimating 6-h future Vmax are listed in Table 9 to be compared with other techniques.

There are four IR-based objective techniques listed in Table 9 that have been verified against aircraftreconnaissance-based samples. Using 2039 best track samples within $1 \mathrm{~h}$ of aircraft-reconnaissance measurements from 1996 to 2005, Olander and Velden (2007) presented the error statistics of the estimated minimum sea level pressure (MSLP) using ADT. In Table 9, their error estimates are converted to Vmax approximately by following the method of Bankert and Tag [2002, using a wind-pressure relationship provided in their Eq. (2)]. The IR-based multivariate regression technique by Kossin et al. (2007) was trained and tested by 1940 best track samples within $3 \mathrm{~h}$ of an aircraft reconnaissance. The IR-based FASI technique (Fetanat et al. 2013) was trained and tested by 2016 best track samples within $12 \mathrm{~h}$ of an aircraft reconnaissance. The most recent IR-based CNN technique by Pradhan et al. (2018) was also tested 

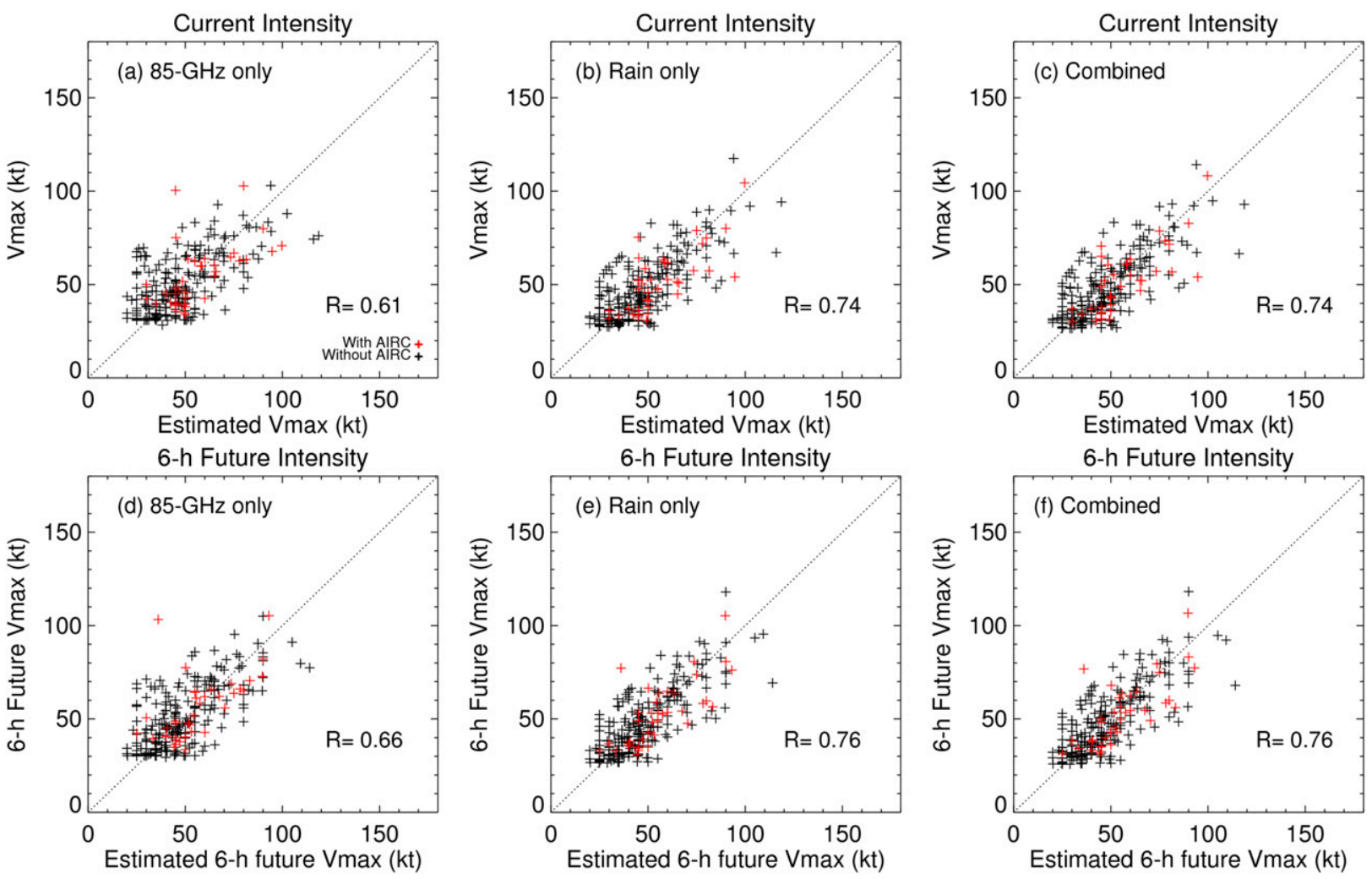

FIG. 2. The scatterplot of the best track Vmax vs the Vmax estimated by using (a) the 85-GHz-only, (b) rain-only, and (c) combined $85-\mathrm{GHz}$ and rain regression models for the independent dataset $(n=257$ samples) in ATL basin. (d),(e),(f) As in (a), (b), and (c), respectively, but for the best track 6-h future Vmax vs the estimated 6-h future Vmax. AIRC samples are highlighted as red. The thin dotted line represents a perfect 1:1 relationship. The correlation coefficient $R$ is also indicated in each panel.

against an aircraft-reconnaissance-based best track dataset of 2646 samples. In comparison, the PMW-IE algorithm's error statistics are in the range of all above techniques' error statistics when tested against aircraftreconnaissance-based best track samples.

Table 9 also lists three objective techniques that were trained and verified against best track. These include the IR-based DAV algorithm (Ritchie et al. 2012, 2014), CIRA AMSU-based algorithm (Demuth et al. 2004, 2006), and the SSM/I-based $k$-nearest-neighbor technique (Bankert and Tag 2002). While the validation datasets and periods are different, the PMW-IE algorithm does appear to be on par with error estimates of all of these three techniques when verified against best track.

From Table 9, we can see that all of these objective techniques, including the PMW-IE algorithm presented in this study, are less skillful than the subjective DT. Using 2003 samples within $2 \mathrm{~h}$ of an aircraft reconnaissance, Knaff et al. (2010) demonstrated that the MAE of DT is between 5 and $11 \mathrm{kt}$, and RMSE of DT between 6 and $14 \mathrm{kt}$. Furthermore, it was shown that the subjective DT is most skillful for category 2-4 hurricanes. In contrast, most of the objective techniques become less skillful for major hurricanes because of the limited training and verification samples available for extremely intense systems.

The subjective DT utilizes structural information regarding the cloud patterns to derive an estimate of TC intensity. The PMW-IE algorithm here instead uses bulk metrics of $85-\mathrm{GHz}$ ice scattering and rain rate in the inner core to estimate TC intensity. Since the TC intensity is related to both cloud precipitation patterns (the more symmetric, the more intense) and the intensity of latent heating (rain rate can be used as a proxy of latent heating), it is difficult to justify which method is better. However, it is important to recognize that the PMW-IE technique provides independent information for TC intensity estimates. Using PMW-IE along with all other independent techniques including the subjective DT will reduce the mean error of a weighted consensus.

\section{Conclusions and future work}

A statistical Passive Microwave Intensity Estimation (PMW-IE) algorithm for TCs in the ATL and EPA basins is described. The algorithm uses a TC's center location and estimators derived from $85-\mathrm{GHz}$ brightness 

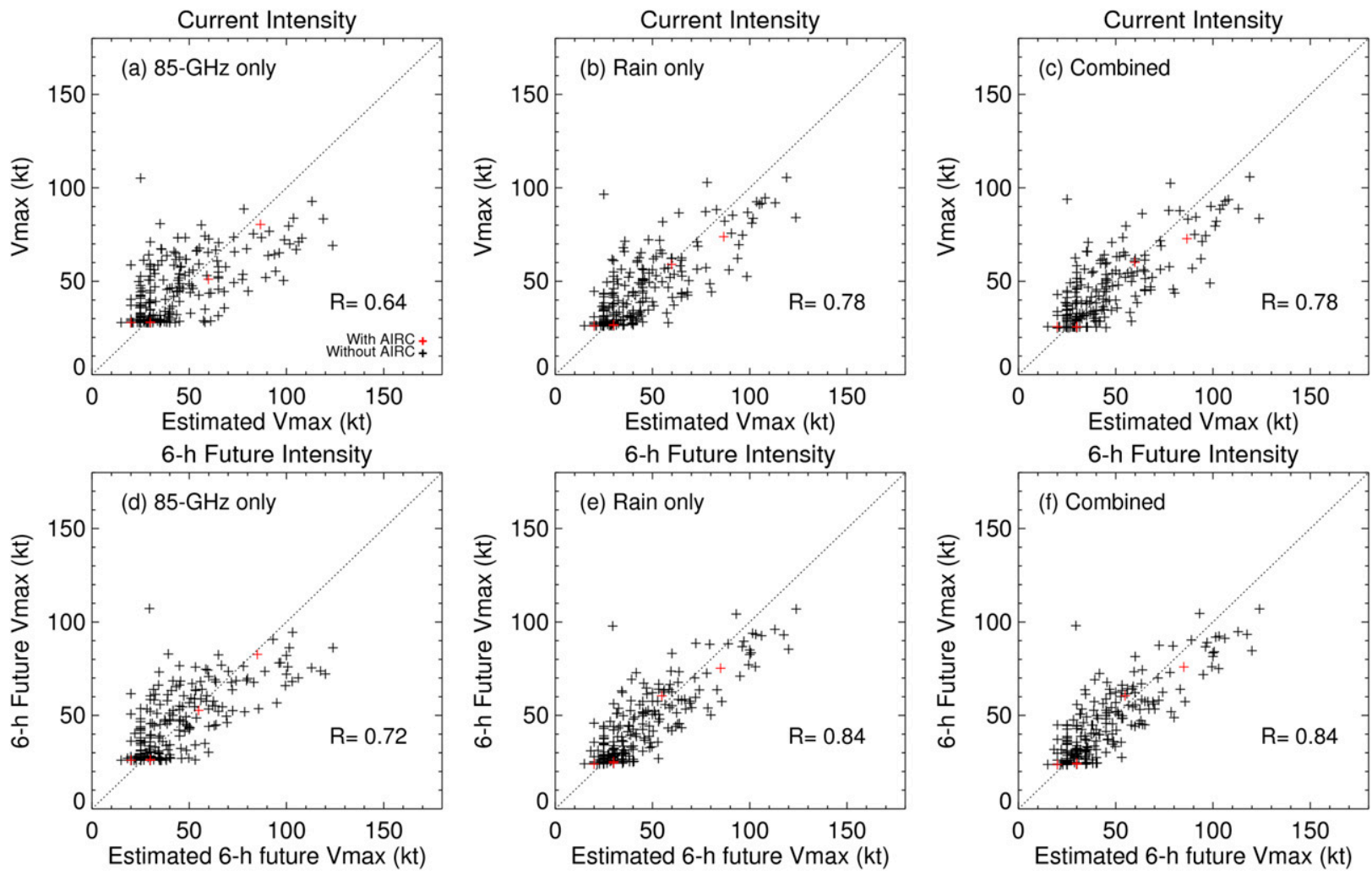

FIG. 3. As in Fig. 2, but for the independent dataset ( $n=237$ samples) in the EPA basin.

temperature and passive-microwave-retrieved rain rate in the inner core of TCs. It was developed using the full record of the TRMM TMI observations during 19982013 and a stepwise multiple linear regression approach. The TMI sample was constrained to include only wellobserved TC overpasses in which $100 \%$ of the innercore region was observed. All landfalling cases were excluded. The final dataset included 1219 TMI overpasses of 239 TCs in ATL and 1107 overpasses of 264 TCs in EPA. It was further separated into dependent samples for regression model development and independent samples for model verification.

Candidate estimators include five variables derived from $85-\mathrm{GHz}$ brightness temperatures and seven variables derived from TMI 2A12 near-surface rain-rate retrievals, all of which are highly correlated with the current best track maximum wind intensity (Vmax) and 6-h future Vmax of TCs at $99 \%$ significance level. These variables are calculated within a fixed inner-core radius, which is selected to produce the best correlations. This optimal inner-core

TABLE 8. Bias analysis of the estimated Vmax and 6-h future Vmax vs best track values for different TC intensity groups. Positive (negative) values mean overestimation (underestimation). Unit is kt.

\begin{tabular}{|c|c|c|c|c|c|c|}
\hline & \multicolumn{2}{|c|}{ 85-GHz only } & \multicolumn{2}{|c|}{ Rain only } & \multicolumn{2}{|c|}{ Combined } \\
\hline & $t=0 \mathrm{~h}$ & $t=6 \mathrm{~h}$ & $t=0 \mathrm{~h}$ & $t=6 \mathrm{~h}$ & $t=0 \mathrm{~h}$ & $t=6 \mathrm{~h}$ \\
\hline \multicolumn{7}{|l|}{ ATL } \\
\hline All TCs $(n=257)$ & 1.73 & 1.89 & -1.04 & -0.50 & -0.92 & -0.34 \\
\hline Tropical depressions $(n=48)$ & 17.11 & 13.47 & 9.46 & 7.05 & 9.17 & 7.26 \\
\hline Tropical storms $(n=157)$ & 0.54 & 1.49 & -2.09 & -0.57 & -2.04 & -0.49 \\
\hline All hurricanes $(n=49)$ & -9.70 & -7.03 & -8.82 & -7.11 & -8.03 & -6.69 \\
\hline \multicolumn{7}{|l|}{ EPA } \\
\hline All TCs $(n=237)$ & 1.78 & 1.52 & 0.49 & 0.25 & 0.53 & 0.25 \\
\hline Tropical depressions $(n=110)$ & 9.85 & 8.06 & 6.05 & 4.93 & 5.95 & 4.93 \\
\hline Tropical storms $(n=85)$ & 1.95 & 1.63 & 0.33 & 0.20 & 0.43 & 0.20 \\
\hline All hurricanes $(n=39)$ & -21.79 & -18.05 & -15.84 & -13.59 & -15.63 & -13.59 \\
\hline
\end{tabular}


TABLE 9. Comparison of the error statistics (MAE and RMSE) of TC intensity Vmax (or MSLP in hPa converted to Vmax in kt) of this study (PMW-IE) and other satellite-based TC intensity estimation methods.

\begin{tabular}{|c|c|c|c|c|c|}
\hline Methods & Sensors & Verification against & MAE & RMSE & Reference(s) \\
\hline Dvorak technique & Visible, IR & $\begin{array}{l}\text { Within 2-h aircraft- } \\
\text { reconnaissance-based } \\
\text { best track }\end{array}$ & $5-11 \mathrm{kt}^{\mathrm{a}}($ avg $\sim 8 \mathrm{kt})$ & $6-14 \mathrm{kt}^{\mathrm{a}}($ avg $\sim 10 \mathrm{kt})$ & Knaff et al. (2010) \\
\hline $\begin{array}{l}\text { Deep convolutional } \\
\text { neutral network }\end{array}$ & IR & $\begin{array}{l}\text { Aircraft-reconnaissance } \\
\text { dataset }^{\text {b }}\end{array}$ & - & $9-16 \mathrm{kt}(\mathrm{avg}=11.7 \mathrm{kt})$ & Pradhan et al. (2018) \\
\hline $\begin{array}{l}\text { Feature analogs in } \\
\text { satellite imagery }\end{array}$ & IR & $\begin{array}{l}\text { Within } 12 \text {-h aircraft- } \\
\text { reconnaissance-based } \\
\text { best track }\end{array}$ & $10.9 \mathrm{kt}$ & $12.7 \mathrm{kt}$ or $9.8 \mathrm{hPa}$ & Fetanat et al. (2013) \\
\hline $\begin{array}{l}\text { Advanced Dvorak } \\
\text { technique }\end{array}$ & IR & $\begin{array}{l}\text { Within 1-h aircraft- } \\
\text { reconnaissance-based } \\
\text { best track }\end{array}$ & $9.2 \mathrm{hPa}\left(\sim 10.9 \mathrm{kt}^{\mathrm{c}}\right)$ & $12.5 \mathrm{hPa}\left(\sim 14.9 \mathrm{kt}^{\mathrm{c}}\right)$ & $\begin{array}{l}\text { Olander and } \\
\text { Velden (2007) }\end{array}$ \\
\hline $\begin{array}{r}\text { Multivariate } \\
\text { regression }\end{array}$ & IR & $\begin{array}{l}\text { Within 3-h aircraft- } \\
\text { reconnaissance-based } \\
\text { best track }\end{array}$ & $13.2 \mathrm{kt}$ & $16.7 \mathrm{kt}$ & Kossin et al. (2007) \\
\hline $\begin{array}{l}\text { Deviation angle } \\
\text { variance }\end{array}$ & IR & Best track & - & $12-15 \mathrm{kt}$ & $\begin{array}{l}\text { Ritchie et al. } \\
\quad(2012,2014)\end{array}$ \\
\hline Warm-core anomaly & AMSU & Best track & $10.8 \mathrm{kt}$ & $14 \mathrm{kt}$ & $\begin{array}{l}\text { Demuth et al. } \\
(2004,2006)\end{array}$ \\
\hline $\begin{array}{l}\text { Feature-based } \\
k \text {-nearest-neighbor }\end{array}$ & $\mathrm{SSM} / \mathrm{I}$ & Best track & $14-16 \mathrm{kt}$ & $18.1-19.8 \mathrm{kt}$ & $\begin{array}{l}\text { Bankert and } \\
\text { Tag (2002) }\end{array}$ \\
\hline $\begin{array}{l}\text { PMW-IE combined } \\
\text { model for } t=6 \mathrm{~h}\end{array}$ & TMI & $\begin{array}{l}\text { Best track/within 3-h } \\
\text { aircraft-reconnaissance- } \\
\text { based best track }\end{array}$ & $9 / 9.6 \mathrm{kt}$ & $12 / 12.6 \mathrm{kt}$ & This study \\
\hline
\end{tabular}

${ }^{\text {a }}$ These values are approximated from tables and figures since they were not explicitly stated in the reference paper.

${ }^{b}$ The time length was not specified in the reference paper on how to choose the reconnaissance data to match with the satellite or best track time.

${ }^{\mathrm{c}}$ Conversion between maximum sustained wind and minimum sea level pressure is made approximately by using the wind-pressure relationship provided in Bankert and Tag (2002)'s Eq. (2).

radius is $100 \mathrm{~km}$ for the ATL and $75 \mathrm{~km}$ for EPA samples. Similar results were shown in Cecil and Zipser (1999) with the highest correlations produced by ice-scattering features averaged with a $1^{\circ}$-radius circle.

Among the candidate estimators, the fraction area of inner-core region covered heavy rain (rain rate $\geq$ $5 \mathrm{~mm} \mathrm{~h}^{-1}$, H_RA, correlation coefficients $\left.=0.8-0.87\right)$ and unconditional mean rain rate in the inner core (correlation coefficients $=0.8-0.84$ ) are best correlated with Vmax and 6-h future Vmax. On the other hand, among $85-\mathrm{GHz}$ icescattering variables, the highest correlation coefficients (0.64-0.75) are from the fractional inner-core area covered by $85-\mathrm{GHz} \mathrm{PCT} \leq 275 \mathrm{~K}$. The multiple linear correlation coefficients with Vmax range from 0.69 to 0.74 for $85-\mathrm{GHz}$ variables and from 0.86 to 0.87 for rain variables. This suggests that rain metrics are a better indicator of TC intensity than $85-\mathrm{GHz}$ ice-scattering metrics. Better correlations were found between these TMI-derived variables and 6-h future Vmax. This is consistent with Cecil and Zipser (1999) who found that $85-\mathrm{GHz}$ ice-scattering parameters are better correlated with future than current TC intensity.

The algorithm was developed for ATL and EPA samples separately. In each basin, three regression models were derived using 1) 85-GHz-only variables, 2) rain-rate-only variables, and 3) combined $85-\mathrm{GHz}$ and rain variables after eliminating variables that cause multicollinearity and overfitting problems using a stepwise regression approach. Rain-only and combined models perform better than the 85-GHz-only model. Lower errors are found for estimating the 6-h future Vmax than estimating the current Vmax using all three models. This suggests that it is optimal to use passive-microwave-retrieved rain variables observed a few hours earlier to estimate TC intensity. The MAE (RMSE) of 6-h future Vmax is 9 (12) kt when testing the combined models with ATL and EPA independent samples. Aircraft-reconnaissance-based independent samples yielded a MAE of $9.6 \mathrm{kt}$ and RMSE of $12.6 \mathrm{kt}$ for estimating 6-h future Vmax.

A comparison of error statistics with other TC intensity estimation techniques suggest that the PMW-IE algorithm is on par with other objective satellite-based methods. The PMW-IE algorithm uses a unique data source, that is, the high-resolution passive microwave sensor TMI, and a different approach to estimate TC intensity compared to other satellite-based techniques. This makes intensity estimates from the PMW-IE algorithm independent than other methods. Because of this independence, the PMW-IE method, if available in real 
time or near-real time, will be able to provide additional information for TC forecasters who can utilize different methods to achieve more accurate intensity estimates. The satellite consensus (SatCon) technique incorporates TC estimates from several objective methods to achieve a better estimate than any of its individual parts (Herndon and Velden 2018). The PMW-IE algorithm may provide independent information for SatCon.

To implement the PMW-IE algorithm in real time to estimate TC intensity, an important next step work is to adapt the TMI-based algorithm to other microwave sensors that are currently available. The NASA Global Precipitation Mission (GPM) 1C-constellation and 2A-GPROF-constellation near-real-time products are the suitable candidate for this adaption. The GPM constellation contains GPM Microwave Imager (GMI), which is the successor of TMI, AMSR-2, and SSMIS. The GPM $1 \mathrm{C}$-constelation near-real-time product provides the 85-91-GHz observations, which includes the intercalibrated brightness temperatures from GMI, ASMR2, and SSMIS. The microwave rain retrievals from the GPM 2A-GPROFconstellation near-real-time product contain the rain rates retrieved from GMI, AMSR2, and SSMIS using the NASA GPROF algorithm (Kummerow et al. 1996). Although the brightness temperatures in different frequencies among 85-91 GHz have been intercalibrated against TMI in the GPM 1C product, the error statistics might still be different for different sensors because of different spatial resolutions among TMI, GMI, AMSR2, and SSMIS. It is necessary to perform verifications against GPM $1 \mathrm{C}$ and $2 \mathrm{~A}$ data before implementing the PMW-IE algorithm operationally. We might have to develop similar but different regression models for the lower-resolution sensor (SSMIS).

Both of the TRMM and GPM constellation observations cover all global TC-prone basins. This study focuses on ATL and EPA basins only. Future work will be done to develop similar models for TCs in other basins including the western North Pacific and Southern Hemisphere basins. Another potential future work is to adapt an automatic TC center detection algorithm, such as the Automated Rotational Center Hurricane Eye Retrieval (ARCHER; Wimmers and Velden 2010). Currently the PMW-IE technique uses the center position interpolated from the best track information. Further analysis is required to evaluate the benefit of using ARCHER relative to the best track interpolation. It is also possible that the ARCHER output might help determine the inner-core radius of each microwave observation of TCs, making further improvement of the PMW-IE algorithm possible.

Acknowledgments. The authors thank Mr. Bo You for his initiation and contribution on the model development.
Communications with Mr. Herndon at CIMSS and Dr. Chirokova at CIRA were very helpful on the literature review of the manuscript. The authors really appreciate the constructive comments from three anonymous reviewers that contribute greatly in improving the manuscript. This research was supported by NOAA Joint Hurricane Testbed (JHT) Grants NA15OAR4590199 and NA17OAR4590142 under the direction of Mr. Richard Fulton and Dr. Chris Landsea, and NASA Hurricane Science Research Program (HSRP) Grant NNX10AG34G, NASA Earth Science System Fellowship (NESSF) Award NX14AL33H, and Weather and Atmospheric Dynamics (WAAD) Grant NNX17AH72G under the direction of Dr. Ramesh Kakar and Dr. Ming-Ying Wei. Work at Lawrence Livermore National Laboratory (LLNL) was supported under the auspices of the U.S. Department of Energy by LLNL under Contract DE-AC5207NA27344. The data used in this study are listed in the references, tables, and figures.

\section{REFERENCES}

Bankert, R. L., and P. M. Tag, 2002: An automated method to estimate tropical cyclone intensity using SSM/I imagery. J. Appl. Meteor., 41, 461-472, https://doi.org/10.1175/15200450(2002)041<0461:AAMTET>2.0.CO;2.

_ , and J. Cossuth, 2016: Tropical cyclone intensity estimation via passive microwave data features. 32nd Conf. on Hurricanes and Tropical Meteorology, San Juan, PR, Amer. Meteor. Soc., 10C.1, https://ams.confex.com/ams/32Hurr/webprogram/ Paper292705.html.

Brueske, K. F., and C. S. Velden, 2003: Satellite-based tropical cyclone intensity estimation using the NOAA-KLM series Advanced Microwave Sounding Unit (AMSU). Mon. Wea. Rev., 131, 687-697, https://doi.org/10.1175/1520-0493(2003) $131<0687:$ SBTCIE $>2.0$. CO;2.

Cecil, D. J., and E. J. Zipser, 1999: Relationships between tropical cyclone intensity and satellite-based indicators of inner core convection: $85-\mathrm{GHz}$ ice-scattering signature and lightning. Mon. Wea. Rev., 127, 103-123, https://doi.org/10.1175/15200493(1999)127<0103:RBTCIA > 2.0.CO;2.

Chirokova, G., M. DeMaria, J. Knaff, S. Longmore, and J. F. Dostalek, 2018: Hurricane intensity and wind structure estimation: From AMSU to TROPICS. 33rd Conf. on Hurricanes and Tropical Meteorology, Ponte Verdi, FL, Amer. Meteor. Soc., 251, https://ams.confex.com/ams/33HURRICANE/webprogram/ Paper339690.html.

DeMaria, M., and J. Kaplan, 1994: A Statistical Hurricane Intensity Prediction Scheme (SHIPS) for the Atlantic basin. Wea. Forecasting, 9, 209-220, https://doi.org/10.1175/15200434(1994)009<0209:ASHIPS>2.0.CO;2.

Demuth, J. L., M. DeMaria, J. A. Knaff, and T. H. Vonder Haar, 2004: Evaluation of Advanced Microwave Sounding Unit tropical-cyclone intensity and size estimation algorithms. J. Appl. Meteor., 43, 282-296, https://doi.org/10.1175/15200450(2004)043<0282:EOAMSU>2.0.CO;2.

,,-- and,- 2006 : Improvement of Advanced Microwave Sounding Unit tropical cyclone intensity and size estimation algorithms. J. Appl. Meteor. Climatol., 45, 1573-1581, https:// doi.org/10.1175/JAM2429.1. 
Dvorak, V. F., 1972: A technique for the analysis and forecasting of tropical cyclone intensities from satellite pictures. NOAA Tech. Memo. NESS 36, 15 pp.

_- 1984: Tropical cyclone intensity analysis using satellite data. NOAA Tech. Rep. 11, 45 pp.

Fetanat, G., A. Homaifar, and K. R. Knapp, 2013: Objective tropical cyclone intensity estimation using analogs of spatial features in satellite data. Wea. Forecasting, 28, 1446-1459, https://doi.org/10.1175/WAF-D-13-00006.1.

Franke, G. R., 2010: Multicollinearity. Wiley International Encyclopedia of Marketing, J. Sheth and N. Malhotra, Eds., John Wiley \& Sons Ltd., https://doi.org/10.1002/9781444316568.wiem02066.

Glass, M., and G. W. Felde, 1992: Intensity estimation of tropical cyclones using SSM/I brightness temperatures. Preprints, Sixth Conf. on Satellite Meteorology and Oceanography, Atlanta, GA, Amer. Meteor. Soc., J8-J10.

Herndon, D., and C. S. Velden, 2006: Upgrades to the UW-CIMSS AMSU-based tropical cyclone intensity algorithm. 27th Conf. on Hurricanes and Tropical Meteorology, Monterey, CA, Amer. Meteor. Soc., 4B.5, https://ams.confex.com/ams/ 27Hurricanes/techprogram/paper_108186.htm.

—_, and — 2018: An update on the CIMSS Satellite Consensus (SATCON) tropical cyclone intensity algorithm. 33rd Conf. on Hurricanes and Tropical Meteorology, Ponte Verdi, FL, Amer. Meteor. Soc., 284, https://ams.confex.com/ams/33HURRICANE/ webprogram/Paper340235.html.

,,-- R. Bennartz, and Z. Li, 2018: Tropical cyclone intensity estimation from the TROPICS CubeSat satellite constellation. 33rd Conf. on Hurricanes and Tropical Meteorology, Ponte Verdi, FL, Amer. Meteor. Soc., 11D.4, https://ams.confex.com/ ams/33HURRICANE/webprogram/Paper340277.html.

Jiang, H., C. Liu, and E. J. Zipser, 2011: A TRMM-based tropical cyclone cloud and precipitation feature database. J. Appl. Meteor. Climatol., 50, 1255-1274, https://doi.org/10.1175/2011JAMC2662.1.

_ , E. M. Ramirez, and D. J. Cecil, 2013: Convective and rainfall properties of tropical cyclone inner cores and rainbands from 11 years of TRMM data. Mon. Wea. Rev., 141, 431-450, https:// doi.org/10.1175/MWR-D-11-00360.1.

Kidder, S. Q., and T. H. Vonder Haar, 1995: Satellite Meteorology: An Introduction. Academic Press, 466 pp.

—, M. D. Goldberg, R. M. Zehr, M. DeMaria, J. F. W. Purdom, C. S. Velden, N. C. Grody, and S. J. Kusselson, 2000: Satellite analysis of tropical cyclones using the Advanced Microwave Sounding Unit (AMSU). Bull. Amer. Meteor. Soc., 81, 1241-1260, https:// doi.org/10.1175/1520-0477(2000)081<1241:SAOTCU>2.3.CO;2.

Knaff, J. A., D. P. Brown, J. Courtney, G. M. Gallina, and J. L. Beven, 2010: An evaluation of Dvorak technique-based tropical cyclone intensity estimates. Wea. Forecasting, 25, 13621379, https://doi.org/10.1175/2010WAF2222375.1.

Kossin, J. P., K. R. Knapp, D. J. Vimont, R. J. Murnane, and B. A. Harper, 2007: A globally consistent reanalysis of hurricane variability and trends. Geophys. Res. Lett., 34, L04815, https:// doi.org/10.1029/2006GL028836.

Kummerow, C., W. S. Olson, and L. Giglio, 1996: A simplified scheme for obtaining precipitation and vertical hydrometeor profiles from passive microwave sensors. IEEE Trans. Geosci. Remote Sens., 34, 1213-1232, https://doi.org/10.1109/36.536538.

Landsea, C., and J. Franklin, 2013: Atlantic hurricane database uncertainty and presentation of a new database format. Mon. Wea. Rev., 141, 3576-3592, https://doi.org/10.1175/MWR-D-12-00254.1.

Olander, T. L., and C. S. Velden, 2007: The advanced Dvorak technique: Continued development of an objective scheme to estimate tropical cyclone intensity using geostationary infrared satellite imagery. Wea. Forecasting, 22, 287-298, https:// doi.org/10.1175/WAF975.1.

- , and —-, 2018: The UW-CIMMS Advanced Dvorak Technique (ADT): Current status and future upgrades. 33rd Conf. on Hurricanes and Tropical Meteorology, Ponte Verdi, FL, Amer. Meteor. Soc., 247, https://ams.confex.com/ ams/33HURRICANE/webprogram/Handout/Paper339058/ AMSSatConf2018-P247-ADT_Final.pdf.

Piñeros, M. F., E. A. Ritchie, and J. S. Tyo, 2008: Objective measures of tropical cyclone structure and intensity change from remotely sensed infrared image data. IEEE Trans. Geosci. Remote Sens., 46, 3574-3580, https://doi.org/10.1109/TGRS.2008.2000819.

,-- , and -2011 : Estimating tropical cyclone intensity from infrared image data. Wea. Forecasting, 26, 690-698, https://doi.org/10.1175/WAF-D-10-05062.1.

Pradhan, R., R. S. Aygun, M. Maskey, R. Ramachandran, and D. J. Cecil, 2018: Tropical cyclone intensity estimation using a deep convolutional neural network. IEEE Trans. Image Process., 27, 692-702, https://doi.org/10.1109/TIP.2017.2766358.

Rao, G. V., and P. D. MacArthur, 1994: The SSM/I estimated rainfall amounts of tropical cyclones and their potential in predicting the cyclone intensity changes. Mon. Wea. Rev., 122, 1568-1574, https://doi.org/10.1175/1520-0493(1994)122<1568: TSERAO $>2.0 . \mathrm{CO} ; 2$

Ritchie, E. A., G. Valliere-Kelley, M. F. Piñeros, and J. S. Tyo, 2012: Tropical cyclone intensity estimation in the North Atlantic basin using an improved deviation angle variance technique. Wea. Forecasting, 27, 1264-1277, https://doi.org/ 10.1175/WAF-D-11-00156.1.

— K. M. Wood, O. G. Rodriguez-Herrera, M. F. Piñeros, and J. S. Tyo, 2014: Satellite-derived tropical cyclone intensity in the North Pacific Ocean using the deviation-angle variance technique. Wea. Forecasting, 29, 505-516, https://doi.org/10.1175/ WAF-D-13-00133.1.

Rodgers, E. B., and H. F. Pierce, 1995: A satellite observational study of precipitation characteristics in western North Pacific tropical cyclones. J. Appl. Meteor., 34, 2587-2599, https://doi.org/10.1175/ 1520-0450(1995)034<2587:ASOSOP > 2.0.CO;2.

_ S. W. Chang, and H. F. Pierce, 1994: A satellite observational and numerical study of precipitation characteristics in western North Atlantic tropical cyclones. J. Appl. Meteor., 33, 129-139, https:// doi.org/10.1175/1520-0450(1994)033<0129:ASOANS>2.0.CO;2.

Simpson, J., R. F. Adler, and G. R. North, 1988: A proposed Tropical Rainfall Measuring Mission (TRMM) satellite. Bull. Amer. Meteor. Soc., 69, 278-295, https://doi.org/10.1175/15200477(1988)069<0278:APTRMM>2.0.CO;2.

Spencer, R. W., H. M. Goodman, and R. E. Hood, 1989: Precipitation retrieval over land and ocean with the SSM/I: Identification and characteristics of the scattering signal. J. Atmos. Oceanic Technol., 6, 254-273, https://doi.org/10.1175/1520-0426 (1989)006<0254:PROLAO > 2.0.CO;2.

Velden, C. S., T. Olander, and R. M. Zehr, 1998: Development of an objective scheme to estimate tropical cyclone intensity from digital geostationary satellite imagery. Wea. Forecasting, 13, 172-186, https://doi.org/10.1175/1520-0434(1998) 013<0172:DOAOST>2.0.CO;2.

Wimmers, A. J., and C. S. Velden, 2010: Objectively determining the rotational center of tropical cyclones in passive microwave satellite imagery. J. Appl. Meteor. Climatol., 49, 2013-2034, https://doi.org/ 10.1175/2010JAMC2490.1. 